\title{
Long term ventricular performance after intra-atrial correction of transposition: left ventricular filling is the major limitation
}

Oleg Reich, Marie Voříšková, Cyril Ruth, Miroslav Krejčír, Jan Marek, Jan Škovránek, Bohumil Hučín, Milan Samánek

\begin{abstract}
Objective-To establish the incidence of systolic and diastolic dysfunction of the right and left ventricle in a large cohort of patients after Mustard or Senning operations and to assess changes in the incidence on long term follow up.

Design-Postoperative case-control study using radionuclide ventriculography. Ejection fractions, peak filling rates, rapid filling periods and fractions, slow filling periods and fractions, and atrial contraction periods and fractions were studied.

Setting-Tertiary care centre, ambulatory and hospital inpatient care.
\end{abstract}

Patients-A convenience sample of 153 patients studied at median age of 6.9 years (median 4.4 years after surgery). In 99 cases another study was available at a median age of 15.3 years (median 13 years after surgery and 8.8 years after the first study).

Results-Respective incidences of dysfunction in the first and the second study were as follows: ejection fraction-right ventricle $7.8 \%$ and $8.1 \%$, left ventricle $7.2 \%$ and $10.1 \%$; peak filling rate-right ventricle $0 \%$ and $4.2 \%$, left ventricle $14.3 \%$ and $29.5 \%$ ( $<20.05)$; rapid filling periodright ventricle $18.3 \%$ and $11.6 \%$, left ventricle $30.2 \%$ and $30.5 \%$; slow filling period-right ventricle $4.8 \%$ and $3.2 \%$; left ventricle $11.9 \%$ and $23.2 \%$; atrial contraction period-right ventricle $0.8 \%$ and $4.2 \%$, left ventricle $15.1 \%$ and $26.3 \%$; rapid filling fraction-right ventricle both $0 \%$, left ventricle $82.5 \%$ and $79.0 \%$; slow filling fraction-right ventricle $0.8 \%$ and $4.2 \%$, left ventricle $37.3 \%$ and $30.5 \%$; atrial contraction fraction-right ventricle both $0 \%$, left ventricle $79.4 \%$ and $71.6 \%$.

Conclusions-The incidence of systolic ventricular dysfunction is $8 \%$ (right ventricle) and $10 \%$ (left ventricle) 13 years after surgery, without a significant increase over the eight year follow up. Diastolic filling is abnormal in up to $80 \%$ of patients and left ventricular peak filling rate deteriorates with time.

(Heart 1997;78:376-381)

Keywords: congenital heart defects; transposition of the great arteries; radionuclide ventriculography; ventricular function
The reported incidence of resting systolic ventricular dysfunction after an intra-atrial repair of transposition of the great arteries varies from $0 \%$ to $66 \% .^{1-17}$ However, prognosis and quality of life are not only affected by systolic dysfunction after a Mustard or Senning procedure. Intra-atrial surgery causes a decreased capacity of the systemic venous atrium and diminishes the ability of atrial contraction to boost ventricular filling. ${ }^{1}$ Intra-atrial baffle obstruction decreases left ventricular systolic output ${ }^{1}$ and exercise tolerance. ${ }^{18}$

The purpose of this study was to evaluate the long term incidence of systolic dysfunction and disturbances in ventricular filling in a large group of patients after intra-atrial repair of transposition. In particular, we wanted to determine whether the incidence of ventricular dysfunction increases with time.

\section{Methods}

PATIENTS

Ventricular function was studied in 153 patients between the ages of 188 days and 21.8

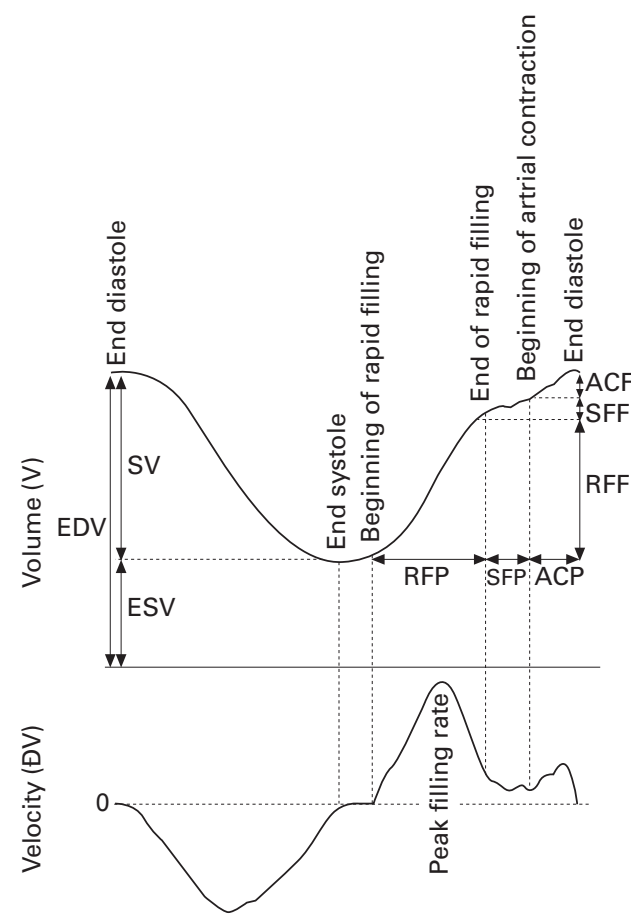

Figure 1 Calculation of the variables (see text). ACF, atrial contraction fraction; $A C P$, atrial contraction period; $D V$, change in velocity; EDV, end diastolic volume; ESV, end systolic volume; RFF, rapid filling fraction; RFP, rapid filling period; SFF, slow filling fraction; SFP, slow filling period; SV, stroke volume. 
Table 1 Normal values

\begin{tabular}{|c|c|c|c|}
\hline & 5th centile & 95th centile & Mean \\
\hline LVEF (\%) & 50.0 & 68.9 & 59.5 \\
\hline RVEF (\%) & 33.2 & 54.0 & 43.6 \\
\hline LVPFR (EDV/s) & 1.98 & 5.01 & 3.11 \\
\hline RVPFR (EDV/s) & 1.19 & 2.51 & 1.75 \\
\hline LVRFP (\%RR) & 14.4 & 34.1 & 21.7 \\
\hline RVRFP (\%RR) & 16.0 & 38.7 & 24.8 \\
\hline LVSFP (\%RR) & 5.2 & 17.1 & 13.1 \\
\hline RVSFP (\%RR) & 2.4 & 19.2 & 11.7 \\
\hline LVACP (\%RR) & 9.5 & 30.8 & 19.4 \\
\hline RVACP (\%RR) & 2.6 & 35.5 & 18.3 \\
\hline LVRFF (\%SV) & 71.0 & 89.7 & 79.2 \\
\hline RVRFF (\%SV) & 25.4 & 91.7 & 66.8 \\
\hline LVSFF (\%SV) & 4.7 & 18.5 & 11.3 \\
\hline RVSFF (\%SV) & 2.0 & 26.5 & 15.7 \\
\hline LVACF (\%SV) & 0.4 & 17.6 & 9.6 \\
\hline RVACF (\%SV) & 0.8 & 49.8 & 17.5 \\
\hline
\end{tabular}

EDV, end diastolic volume; LVACF, left ventricular filling fraction of atrial contraction; LVACP, left atrial contraction period; LVEF, left ventricular ejection fraction; LVPFR, left ventricular peak filling rate; LVRFF, left ventricular rapid filling fraction; LVRFP, left ventricular rapid filling period; LVSFF, left ventricular slow filling fraction; LVSFP, left ventricular slow filling period; RR, heart cycle duration (RR interval); RVACF, right ventricular filling fraction of atrial contraction; RVACP, right atrial contraction period; RVEF, right ventricular ejection fraction; RVPFR, right ventricular peak filling rate; RVRFF, right ventricular rapid filling fraction; RVRFP, right ventricular rapid filling period; RVSFF, right ventricular slow filling fraction; RVSFP, right ventricular slow filling period; SV, stroke volume.

years (median 6.9 years), four days to 16 years after the intra-atrial repair (median 4.4 years). A Mustard procedure had been performed in 113 patients at the median age of 483 days; 40 patients had undergone a Senning procedure at median age of 294 days. The age at surgery ranged from 25 days to 19 years (median 447 days). In 38 patients a ventricular septal defect was closed at the time of intra-atrial correction. Forty five patients had had palliative surgery between the ages of 10 days and five years (median 1.6 years).

In 99 of the 153 patients, a repeat study was done between the ages of 5.1 and 28.8 years (median 15.3 years), 4.4 to 17.3 years after the surgery (median 13.0 years). The interval between the first and the final study was between 1.8 and 11.6 years (median 8.8 years). In these patients the intra-atrial correction (Mustard in 85; Senning in 14) had been per-

Table 2 Differences between the patients and control values

\begin{tabular}{|c|c|c|c|}
\hline & $T G A$ & Controls & $p$ value \\
\hline LVEF $(\%) \dagger$ & $60.6(7.5)$ & $59.5(6.1)$ & 0.321 \\
\hline RVEF $(\%) \dagger$ & $43.3(6.1)$ & $43.6(6.1)$ & 0.765 \\
\hline LVPFR (EDV/s)† & $2.61(0.79)$ & $3.11(0.86)$ & 0.002 \\
\hline RVPFR (EDV/s) $\dagger$ & $2.21(0.61)$ & $1.75(0.43)$ & $<0.001$ \\
\hline LVRFP $(\% R R)^{\star}$ & $17.1 / 14.3 / 28.6$ & $21.4 / 18.8 / 22.4$ & 0.084 \\
\hline RVRFP $(\% \mathrm{RR}) \star$ & $20.5 / 17.5 / 23.2$ & $23.8 / 19.3 / 30.2$ & 0.005 \\
\hline LVSFP $(\% \mathrm{RR})^{\star}$ & $12.1 / 9.5 / 16.3$ & $12.4 / 11.9 / 14.3$ & 0.754 \\
\hline RVSFP (\%RR)* & $8.5 / 5.0 / 12.9$ & $12.1 / 9.5 / 14.3$ & 0.032 \\
\hline LVACP $(\% \mathrm{RR})^{\star}$ & $21.3 / 15.0 / 29.3$ & $19.3 / 15.5 / 24.4$ & 0.089 \\
\hline RVACP $(\% \mathrm{RR})^{\star}$ & $22.0 / 17.9 / 25.0$ & $17.9 / 12.1 / 25.6$ & 0.028 \\
\hline LVRFF $(\% S V)^{\star}$ & $50.4 / 41.3 / 63.6$ & $81.1 / 76.8 / 84.8$ & $<0.001$ \\
\hline RVRFF (\%SV)* & $67.6 / 61.1 / 74.0$ & $68.8 / 57.2 / 80.4$ & 0.583 \\
\hline LVSFF $(\% S V)^{\star}$ & $16.1 / 11.3 / 21.8$ & $11.5 / 7.9 / 13.5$ & $<0.001$ \\
\hline RVSFF $(\% S V)^{\star}$ & 13.9/9.7/17.6 & $15.7 / 9.4 / 22.1$ & 0.264 \\
\hline LVACF $(\% S V)^{\star}$ & $29.4 / 18.2 / 40.3$ & $7.7 / 5.6 / 9.9$ & $<0.001$ \\
\hline RVACF $(\% \text { SV) })^{\star}$ & $17.9 / 12.4 / 25.2$ & $16.0 / 5.9 / 23.1$ & 0.107 \\
\hline Heart rate (beats $/ \mathrm{min}) \dagger$ & $92.7(17.9)$ & $92.7(15.8)$ & 0.999 \\
\hline
\end{tabular}

${ }^{\star}$ The three values are median/25th centile/75th centile. $†$ Values are mean (SD).

LVACF, left ventricular filling fraction of atrial contraction; LVACP, left atrial contraction period; LVEF, left ventricular ejection fraction; LVPFR, left ventricular peak filling rate; LVRFF, left ventricular rapid filling fraction; LVRFP, left ventricular rapid filling period; LVSFF, left ventricular slow filling fraction; LVSFP, left ventricular slow filling period; $R R$, heart cycle duration (RR interval); RVACF, right ventricular filling fraction of atrial contraction; RVACP, right atrial contraction period; RVEF, right ventricular ejection fraction; RVPFR, right ventricular peak filling rate; RVRFF, right ventricular rapid filling fraction; RVRFP, right ventricular rapid filling period; RVSFF, right ventricular slow filling fraction; RVSFP, right ventricular slow filling period; $\mathrm{SV}$, stroke volume; TGA, transposition of the great arteries. formed between the ages of 30 days and 17.2 years (median 15 months).

For the entire cohort of 153 patients the age at the last study was between 427 days and 28.8 years (median 13.8 years) and the interval since the surgery was 11 days to 17.3 years (median 11.6 years). Thirty four patients $(22.1 \%)$ were not in sinus rhythm at the time of study (junctional rhythm in 25, atrial flutter in three, and ventricular pacing in six). In 16 patients $(10.5 \%)$, an obstruction of the systemic venous atrium was proved by echocardiography or first pass radionuclide angiocardiography. In 15 patients $(9.8 \%)$ tricuspid regurgitation was significant at the time of study (echo grade $4 / 4$ ). In 22 patients $(14.4 \%$ ) a residual left to right shunt $(\mathrm{Qp}: \mathrm{Q} s>1.2)$ was found by first pass radionuclide angiocardiography.

\section{PROCEDURES}

Radionuclide ventriculography was performed with a gamma camera (PHO/Gamma LEM; Siemens Gammasonics, Des Plaines, Illinois, USA) and computer system (PDP 11/34Gamma 11 DEC, Siemens Gammasonics). Patients' red blood cells were labelled in vivo with $430 \mathrm{MBq} 99 \mathrm{mTc}$ per $\mathrm{m}^{2}$ of body surface area. A left anterior oblique projection providing optimum ventricular separation was used. The detector was equipped with a $30^{\circ}$ slant hole high sensitivity collimator and tilted $5^{\circ}$ caudally to provide optimal atrioventricular separation. Data were recorded using electrocardiographic gating into 48 frames per cardiac cycle until the total count was eight million. Cycles differing by more than $25 \mathrm{~ms}$ from the average $R R$ interval were excluded. The frames were recorded into a $64 \times 64 \times$ word matrix.

End diastolic ventricular regions of interest were defined using phase analysis and automatic detection of the ventricular septum. Background regions of interest were automatically generated between end diastolic and end systolic ventricular outlines. From the background-free ventricular time-activity curve the first and second derivative curves were computed. Ejection fractions were calculated from the end diastolic and the end systolic counts using the usual formula. Peak filling rate was defined as the maximum positive deflection on the first derivative curve and normalised for end diastolic volume (EDV/s). The second derivative was used for definition of the beginning and end of the rapid filling period and the beginning of the atrial contraction period. Using these points the diastolic portion of the volume curve was divided into the rapid filling period, the slow filling period, and the atrial contraction period. These time intervals were normalised for the RR interval ( $\% R R$ ). The respective volumes supplied to the ventricle in these intervals - the rapid filling fraction, the slow filling fraction, and the atrial contraction fraction-were computed and normalised for the stroke volume (\%SV) (fig 1).

If the $\mathrm{RR}$ interval variation during the data acquisition caused a decrease in the final part of the ventricular time-activity curve the descending part was cut off. If the descending 
JG-TGA, 1 day before surgery
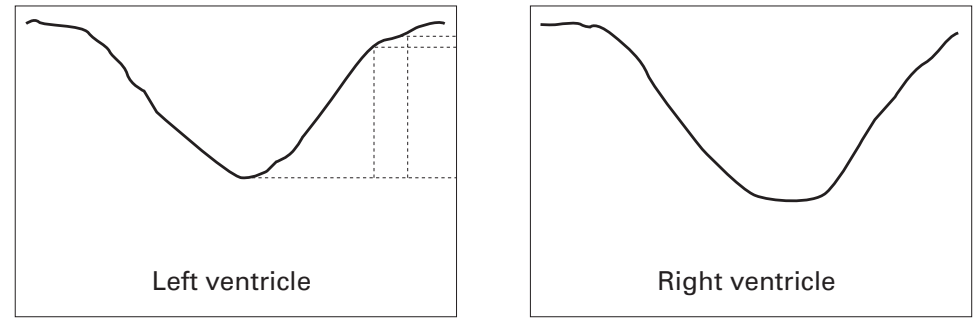

JG-TGA, 7 days after Mustard
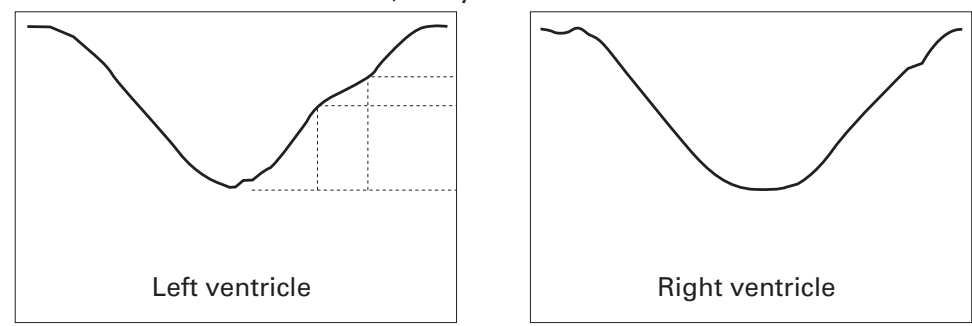

Figure 2 Comparison of volume curves before and early after the surgery. Note changes in the left ventricular diastolic filling. TGA, transposition of the great arteries; Mustard, Mustard operation.

part comprised more than $15 \%$ of the original $\mathrm{RR}$ interval, the diastolic indices were considered uncertain and were not calculated. Using this criterion the diastolic indices were discarded in 27 of 153 of the initial studies $(17.6 \%)$ and in four of 99 of the final studies $(4 \%)$.

We have assumed that the "atrial contraction" portion of the ventricular volume curves may have a different genesis in patients who have had a Mustard or a Senning operation from in a normal heart (see Discussion).

REFERENCE VALUES

The reference values were derived from a retrospectively selected group of children and adolescents in whom intracardiac shunts were studied using radionuclide angiocardiography, and significant shunts were excluded (follow

Table 3 Incidence of abnormal findings at the initial and final study

\begin{tabular}{|c|c|c|c|c|c|c|c|}
\hline & \multicolumn{3}{|c|}{ Initial study } & \multicolumn{3}{|c|}{ Final study } & \multirow[b]{2}{*}{$p$ value } \\
\hline & $n$ & Abnormal & $\%$ & $n$ & Abnormal & $\%$ & \\
\hline LVEF & 153 & 11.00 & 7.19 & 99 & 10.00 & 10.10 & 0.605 \\
\hline RVEF & 153 & 12.00 & 7.84 & 99 & 8.00 & 8.08 & 0.861 \\
\hline LVPFR & 126 & 18.00 & 14.29 & 95 & 28.00 & 29.47 & 0.040 \\
\hline RVPFR & 126 & 0.00 & 0.00 & 95 & 4.00 & 4.21 & 0.077 \\
\hline LFRFP & 126 & 38.00 & 30.16 & 95 & 29.00 & 30.53 & 0.922 \\
\hline RVRFP & 126 & 23.00 & 18.25 & 95 & 11.00 & 11.58 & 0.325 \\
\hline LVSFP & 126 & 15.00 & 11.90 & 95 & 22.00 & 23.16 & 0.092 \\
\hline RVSFP & 126 & 6.00 & 4.76 & 95 & 3.00 & 3.16 & 0.818 \\
\hline LVACP & 126 & 19.00 & 15.08 & 95 & 25.00 & 26.32 & 0.129 \\
\hline RVACP & 126 & 1.00 & 0.79 & 95 & 4.00 & 4.21 & 0.233 \\
\hline LVRFF & 126 & 104.00 & 82.54 & 95 & 75.00 & 78.95 & 0.907 \\
\hline RVRFF & 126 & 0.00 & 0.00 & 95 & 0.00 & 0.00 & - \\
\hline LVSFF & 126 & 47.00 & 37.30 & 95 & 29.00 & 30.53 & 0.548 \\
\hline RVSFF & 126 & 1.00 & 0.79 & 95 & 4.00 & 4.21 & 0.233 \\
\hline LVACF & 126 & 100.00 & 79.37 & 95 & 68.00 & 71.58 & 0.649 \\
\hline RVACF & 126 & 0.00 & 0.00 & 95 & 0.00 & 0.00 & - \\
\hline
\end{tabular}

See table 2 for units.

LVACF, left ventricular filling fraction of atrial contraction; LVACP, left atrial contraction period; LVEF, left ventricular ejection fraction; LVPFR, left ventricular peak filling rate; LVRFF, left ventricular rapid filling fraction; LVRFP, left ventricular rapid filling period; LVSFF, left ventricular slow filling fraction; LVSFP, left ventricular slow filling period, RVACF, right ventricular filling fraction of atrial contraction; RVACP, right atrial contraction period; RVEF, right ventricular ejection fraction; RVPFR, right ventricular peak filling rate; RVRFF, right ventricular rapid filling fraction; RVRFP, right ventricular rapid filling period; RVSFF, right ventricular slow filling fraction; RVSFP, right ventricular slow filling period; TGA, transposition of the great arteries. up radionuclide ventriculography is routinely done in all such patients in our institution). ${ }^{19}$ The control group comprised 53 children and adolescents studied between the ages of three and 23 years (median 12 years), 46 of whom were studied for suspected atrial septal defect, four for patent arterial duct, and three for ventricular septal defect. In all, the Qp:Qs ratio was less than 1.2:1 and other heart defects were excluded by echocardiography. Their heart rate (mean (SD)) was 93 (16) beats/min and did not differ from the heart rate of the transposition patients at the initial study (93 (18) beats/ min, $p=0.999)$, but it was significantly higher than in the transposition patients in the final study (80 (17) beats/min, $\mathrm{p}<0.001)$. The transposition and control groups were both studied using the same protocol, hardware, software, and personnel. In the following text, the values are referred as "normal" if they fit within the intervals between 5 th and 95 th centiles of the results for the control group (table 1).

STATISTICS

All the datasets were tested for normal distribution in all the statistical tests and for equal variance when they were compared. If a normal distribution and equal variance were proved, the data are displayed as mean (SD) and a $t$ test was used to compare the data. If normal distribution or equal variance could not be shown, the data are displayed as median/ 25th centile/75th centile, and the MannWhitney rank sum test was used for the comparison. Differences in incidences were tested by the $\chi^{2}$ test , and in incidences below $5 \%$ by the Fisher exact test. A Kaplan-Meier estimate was used for calculation of actuarial probability. Differences with a $\mathrm{p}$ value less then 0.05 are considered significant.

\section{Results}

Patients and controls did not differ in ejection fractions, time intervals of the left ventricular diastolic filling, or right ventricular filling fractions. Left ventricular peak filling rate was lower than normal and right ventricular peak filling rate was higher than normal. Compared with normal values, right atrial contraction period was prolonged at the expense of shortened right ventricular rapid and slow filling periods. The most striking differences were in the left ventricular filling fractions: the rapid filling fraction was markedly decreased, the slow filling fraction was slightly increased, and the filling fraction of atrial contraction was markedly increased (table 2). In four of the patients, ventricular function was studied both before and after the surgery. The abnormalities of left ventricular filling were clearly related to the surgery and were documented as early as seven days after the operation (fig 2).

The incidence of abnormally low ejection fractions, peak filling rates, rapid filling periods, and rapid filling fractions, as well as abnormally high slow filling periods and fractions and atrial contraction periods and fractions, are shown in table 3. The incidence of systolic dysfunction of the systemic ventricle 
RVEF
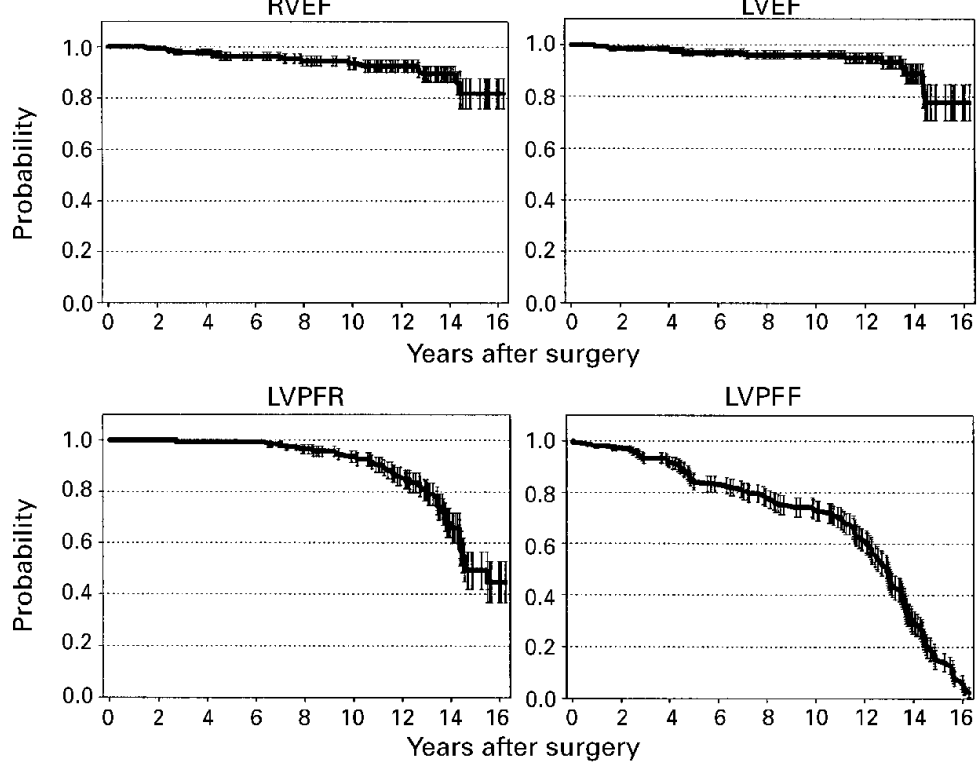

Figure 3 Actuarial probability of normal values. LVEF, left ventricular ejection fraction; LVPFR, left ventricular peak filling rate; LVRFF, left ventricular rapid filling fraction; $R V E F$, right ventricular ejection fraction.

was $8 \%$ both at the initial and the final study. The left ventricular ejection fraction was below the norm in $7 \%$ of the patients at the initial study and in $10 \%$ at the final study. Again, the most striking finding was the high incidence of left ventricular diastolic abnormalities. The values for the left ventricular rapid filling fraction and the atrial filling fraction were abnormal in up to $80 \%$ of the patients. The only significant change between the initial and the final study was in the incidence of subnormal left ventricular peak filling rate, which increased from $14 \%$ to $29 \%$. This difference was more
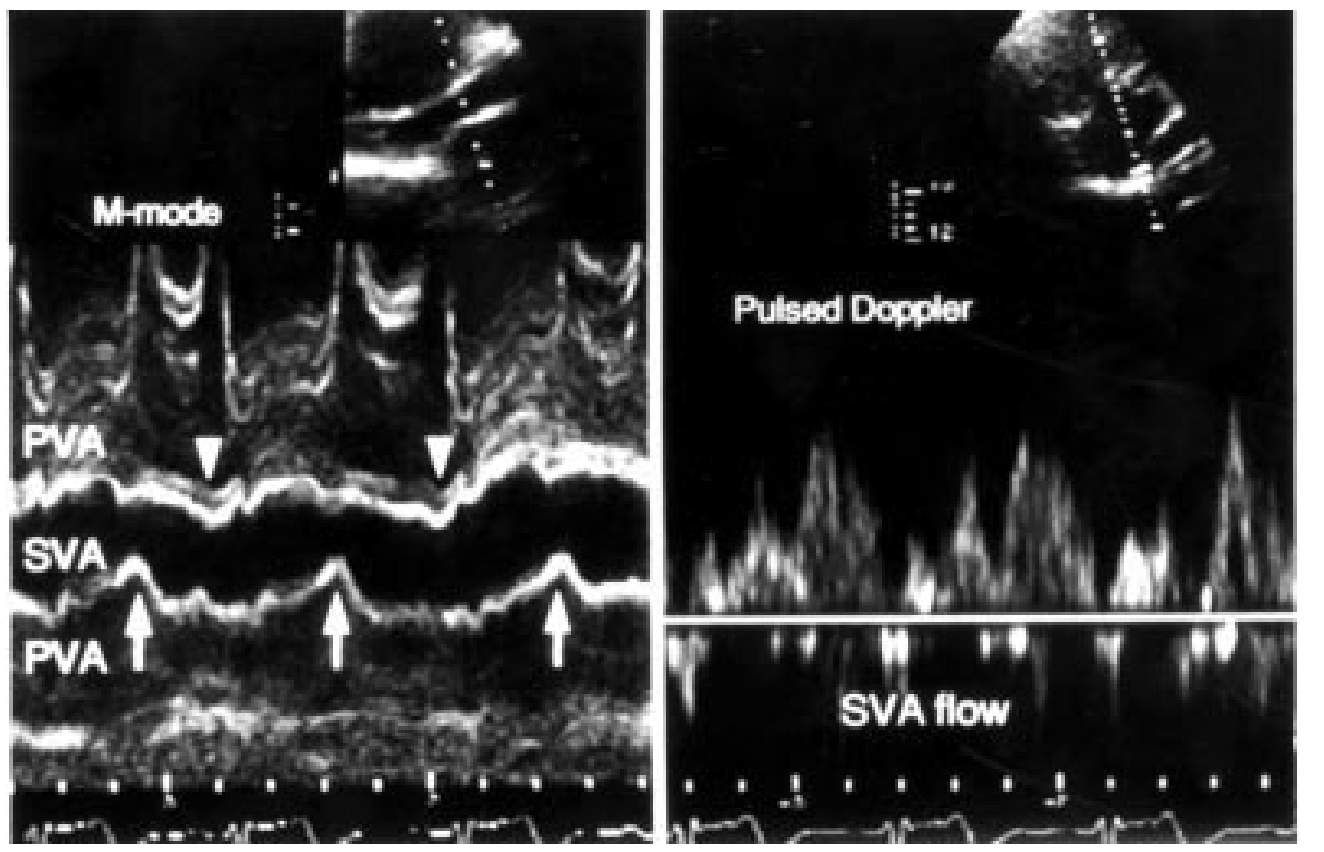

Figure $4 \quad M$ mode (left panel) and pulsed Doppler (right panel) findings after Senning procedure. In mid-diastole (arrows), the systemic venous atrium (SVA) is compressed by pressure from surrounding pulmonary venous atrium (PVA). This causes a decrease in left ventricular filling rate until the SVA reopens due to a pressure increase proximal to the narrowed segment. The filling rate then increases again, with only a small contribution from atrial contraction (arrowhead). See Discussion.

pronounced in patients operated on before the age of 15 months ( $n=64$, change from $9 \%$ to $35 \%, \mathrm{p}=0.017)$ compared with those operated on later $(n=62$, change from $19 \%$ to $25 \%, \mathrm{p}=0.720)$.

The left ventricular slow filling period was significantly longer after the Mustard procedure than after the Senning operation (13.2/ $10.0 / 15.3 \%$ RR, compared with 10.5/7.7/ $13.6 \% R R, p=0.002)$. For the other variables studied the Mustard and the Senning groups did not differ significantly.

Patients in sinus rhythm were compared with those with an abnormal sequence of atrial and ventricular contractions. No significant differences were found, and the shape of left ventricular diastolic filling included a prominent "atrial contraction portion" even in patients with rhythm disturbances. Patients with proved obstruction of the systemic venous atrium had a prolonged left ventricular slow filling period compared with patients without obstruction (17.1/13.1/20.7\% RR $v 12.5 / 9.5 /$ $15.4 \% \mathrm{RR}, \mathrm{p}=0.008)$. The left ventricular slow filling period was also prolonged in patients with significant tricuspid valve regurgitation (15.8/11.3/18.1\% RR $v 12.5 / 9.5 / 15.4 \%$ $\mathrm{RR}$ in patients with no or insignificant tricuspid regurgitation, $\mathrm{p}=0.027)$. Other variables were not influenced by either systemic atrial obstruction or tricuspid regurgitation. Patients with a residual shunt did not differ significantly from those without a shunt in any of the variables studied.

The actuarial probabilities of having a normal right and left ventricular ejection fraction 16 years after the intra-atrial correction were $82 \%$ and $78 \%$ respectively. However, the actuarial probability of having a normal left ventricular peak filling rate was only $45 \%$ and

Pulsed Doppler 
of having a normal left ventricular rapid filling fraction was only $3 \%$ (fig 3 ).

\section{Discussion}

In transposition of the great arteries, ventricular geometry ${ }^{20}$ and pressure-volume relations ${ }^{21}$ are inverted in comparison with a normal heart. In such a situation inverted diastolic ventricular properties could be expected, and indeed both the filling rates are abnormal, though they also differ from the contralateral normal values. We therefore presume that the abnormal filling of the ventricles is caused not only by the diastolic properties of the ventricles but also (and maybe chiefly) by the properties of the intra-atrial baffles.

The filling abnormalities were more pronounced in the left ventricle, where the rate of abnormal findings approached $80 \%$. The peak filling rate was decreased. The fractions of the stroke volume supplied to the ventricle in the different phases of diastole were abnormalthe rapid filling fraction was decreased and slow filling fraction was increased, as was the "filling fraction of atrial systole". All the changes were present shortly after the surgery and remained an almost constant finding throughout the follow up, regardless of the type of surgery. Our findings are in agreement with the reported diminution of early left ventricular filling in patients after both the Mustard and the Senning procedure, as assessed by Doppler ultrasound. ${ }^{22}$ Furthermore, the shape of left ventricular diastolic filling was similar in patients in sinus rhythm and those with an abnormal sequence of atrial and ventricular contractions.

We hypothesise that left ventricular filling is modified by the properties of the intra-atrial baffle in the following manner: from the beginning of diastole flow rate increases and pressure within the baffle falls due to the Bernoulli effect, up to a point when the baffle is compressed by pressure from the surrounding pulmonary venous atrium. This causes the decrease in peak filling rate and in the rapid filling fraction. Left ventricular filling then continues at a slower rate until the pressure proximal to the narrowed baffle increases enough to reopen the baffle. At that point the filling rate again increases to form the "atrial contraction portion" on the volume curve (with only a small contribution from atrial contraction) (fig 4). This hypothesis is also supported by our finding that the increase in incidence of subnormal peak filling rate between the initial and the final study was most pronounced in patients operated on earlier, in whom presumably the baffles are narrower. A prolonged left ventricular slow filling period may reflect a more rigid baffle in Mustard patients, a narrow systemic venous atrium in patients with obstruction, or increased pressure in the pulmonary venous atrium in patients with significant tricuspid regurgitation.

We suppose that the reportedly reduced exercise tolerance ${ }^{2324}$ and inability to increase cardiac output on exercise ${ }^{2526}$ in patients after an atrial correction of transposition of the great arteries may be caused, at least in part, by inability to increase the flow over the intraatrial baffle. Thus impaired left ventricular filling may be a major factor influencing performance of patients after intra-atrial correction of transposition.

This project was supported by the Internal Grant Agency of the Ministry of Health, Czech Republic, grant No 2047-3

1 Graham TP, Atwood GF, Boucek RJ, Boerth RC, Bender HW. Abnormalities of right ventricular function following Mustard's operation for transposition of the great arteries. Circulation 1975;52:678-84.

2 Hagler DJ, Ritter DG, Mair DD, Tajik AJ, Seward JB, Fulton RE, et al. Right and left ventricular function after the Mustard procedure in transposition of the great arteries. Am 7 Cardiol 1979;44:276-83.

3 Benson LN, Bonet J, McLaughlin P, Olley PM, Feiglin D, Benson $\mathrm{LN}$, Bonet J, McLaughin P, Olley PM, Feiglin D,
Druck $\mathrm{M}$, et al. Assessment of right ventricular function during supine bicycle exercise after Mustard's operation. during supine bicycle exercise

4 Murphy JH, Barlai-Kovach MM, Mathews RA, Beerman LB, Park SC, Neches WH, et al. Rest and exercise right and left ventricular function late after Mustard operation: assessment by radionuclide ventriculography. Am $\mathcal{F}$ Cardiol 1983;51:1520-6.

5 Ramsay JM, Venables AW, Kelly MJ, Kalff V. Right and left ventricular function at rest and with exercise after the Mustard operation for transposition of the great arteries. $\mathrm{Br}$ Heart $\mathcal{F} 1984 ; 51: 364-70$.

6 Graham TP, Burger J, Bender HW, Hammon JW, Boucek RJ, Appleton S. Improved right ventricular function after intra-atrial repair of transposition of the great arteries. Circulation 1985;72:II45-51.

7 Hurwitz RA, Caldwell RL, Girod DA, Mahony L, Brown J, King $H$. Ventricular function in transposition of the great arteries: evaluation by radionuclide angiocardiography. $\mathrm{Am}$ Heart $\mathcal{F}$ 1985;110:600-5.

8 Okuda H, Nakazawa M, Imai Y, Kurosawa H, Takanashi Y, Hoshino $\mathrm{S}$, et al. Comparison of ventricular function after Senning and Jatene procedures for complete transposition of the great arteries. Am f Cardiol 1985;55:530-

9 Trusler GA, Williams WG, Duncan KF, Hesslein PS, Benson LN, Freedom RM, et al. Results with the Mustard operation in simple transposition of the great arteries 1963-1985. Ann Surg 1987;206:251-60.

10 Warnes CA, Somerville J. Transposition of the great arteries: late results in adolescents and adults after the Mustard procedure. Br Heart f 1987;58:148-55.

11 Wong KY, Venables AW, Kelly MJ, Kalff V. Longitudinal study of ventricular function after the Mustard operation for transposition of the great arteries: a long term follow up. Br Heart f 1988;60:316-23.

12 Bender HW, Stewart JR, Merrill WH, Hammon JW, Graham TP. Ten years' experience with the Senning operation for transposition of the great arteries: physiological results and late follow-up. Ann Thorac Surg 1989;47:21823 .

13 Redington AN, Rigby ML, Oldershaw P, Gibson DG, Shinebourne EA. Right ventricular function 10 years after the Mustard operation for transposition of the great arteries: analysis of size, shape, and wall motion. Br Heart $\mathcal{F}$ 1989;62:455-61.

14 Reich O, Ruth C, Samanek M. Systolic and diastolic function after atrial repair of simple transposition of the great arteries. In: Vogel M, Buhlmeyer K, eds. Transposition of the great arteries 25 years after Rashkind balloon septostomy. New York: Springer-Verlag, 1992:145-50.

15 Lorenz CH, Walker ES, Graham TP, Powers TA. Right ventricular performance and mass by use of cine MRI late after trial repair of transposition of the great arteries. Circulation 1995;92:II233-9.

16 Hochreiter C, Snyder MS, Borer JS, Engle MA. Right and left ventricular performance 10 years after Mustard repair of transposition of the great arteries. Am f Cardiol 1994;74: of transp-82.

17 Hurwitz RA, Caldwell RL, Girod DA, Brown J. Right ventricular systolic function in adolescents and young
adults after Mustard operation for transposition of the great arteries. Am $\mathcal{F}$ Cardiol 1996;77:294-7.

18 Bowyer JJ, Busst CM, Till JA, Lincoln C, Shinebourne EA. Bowyer JJ, Busst CM, Till JA, Lincoln C, Shinebourne EA.
Exercise ability after Mustard's operation. Arch Dis Child 1990;65:865-70.

19 Reich O, Krejcir M, Ruth C. Vysledky radionuklidove angiokardiografie u normalnich deti a adolescentu [Results of radionuclide ventriculography in normal children and adolescents]. Casopis Lekaru Ceskych 1989;128:1321-4.

20 van Doesburg NH, Bierman FZ, Williams RG. Left ventricular geometry in infants with d-transposition of the great arteries and intact interventricular septum. Circulation 1996;68:733-9.

21 Redington AN, Rigby ML, Shinebourne EA, Oldershaw PJ. Changes in the pressure-volume relation of the right ventricle when its loading conditions are modified. Br Heart ₹1990;63:45 9 .

22 Wyse RK, Macartney FJ, Rohmer J, Ottenkamp J, Brom AG. Differential atrial filling after Mustard and Senning repairs. Detection by transcutaneous Doppler ultrasound. Br Heart f 1980;44:692-8. 
23 Reybrouck T, Dumoulin $M$, van der Hauwaert LG Cardiorespiratory exercise testing after venous switch Cardiorespiratory exercise testing after venous switch
operation in children with complete transposition of the operation in children with complete transpos
great arteries. Am f Cardiol 1988;61:861-5.

24 Reybrouck T, Gewilling $M$, Dumoulin $M$, van der Hauwaert LG. Cardiorespiratory exercise performance after Senning operation for transposition of the great arteries. Br Heart f 1993;70:175-9.
25 Ensing GJ, Heise CT, Driscoll DJ. Cardiovascular response to exercise after the Mustard operation for simple and complex transposition of the great vessels. Am F Cardiol

26 Page E, Perrault H, Flore P, Rossignol AM, Pironneau S, Rocca C, et al. Cardiac output response to dynamic exercise after atrial switch repair for transposition of the great arteries. Am F Cardiol 1996;77:892-5.

\section{HISTORICAL NOTE}

The following letter by Dr Walter Somerville to Dr Evan Bedford was written 40 years ago. It was recently unearthed by Dr Howard Swanton of the Middlesex Hospital, London.

I had been meaning to have a word with you about one or two points since you came back but I know you have much to catch up on. None of them is urgent but I thought I would put this point now. Sooner or later we will have to take a more active part in pumpoxygenators. They were discussed recently at the Junior Cardiac Club, at which everyone involved in the subject in London attended, including several people who had recently returned from the US. They included Bentall (Hammersmith), Rose (Guy's), McMillan (St. Thomas's) and Paneth (Brompton) and others. It is quite clear that at two American centres, at least, V.S.D.s are being closed as routine, and Fallots have the defect repaired and the stenosis removed.

My suggestion is that at this stage we might approach the problem in the way that has been so successful with the A.S.D.s. That is to say we should send an anaesthetist and a surgeon to either the Mayo Clinic or Minneapolis, for say a month, to learn the anaesthetic and surgical techniques as they stand today. It is a fact that Sellick has been devoting some time to trying to work the Lillehei apparatus on dogs. He can spend a half-day a week or less in the laboratory, with little or no surgical assistance. This type of approach to the problem is quite hopeless; it is not even pioneering because the Minneapolis people have passed this point many years ago. At Guy's, Ross has been working for the past few years on the Lillehei pump-oxygenator with full-time surgical assistance, but as he told us at the J.C.C. his dog survival rate is still very low and the results on humans is so depressing that anyone else but Brock would have had to abandon it. Drew at Westminster told us his results are not much better. Paneth (Brompton) has just returned from spending a year with Lillehei who he says closes V.S.D.s as a routine procedure on humans. Lillehei's own words are " . . .the closure of ventricular defects even in the tiniest infants is technically quite easy ..." (Circulation 1957, p. 634).

Now that the ostium secundum problem has been mastered, it is up to us to remain in the lead with the V.S.D.s, ostium primums and Fallots. Unless we take action soon we shall lose our place, and the way to keep it is to profit by the years of American groundwork and copy the identical techniques used today. 